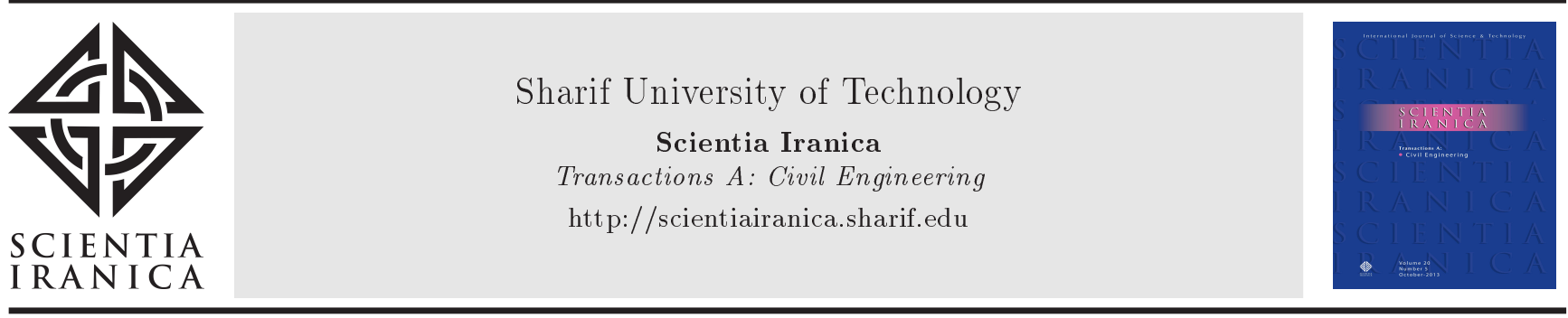

\title{
Investigation into geotechnical properties of clayey soils contaminated with gasoil using Response Surface Methodology (RSM)
}

\author{
F. Mir Mohammad Hosseini, T. Ebadi*, A. Eslami, S.M. Mir Mohammad Hosseini, \\ and H.R. Jahangard
}

Faculty of Civil \& Environmental Engineering, Amirkabir University of Technology, Tehran, P.O. Box 15875-4413, Iran.

Received 31 December 2016; received in revised form 25 July 2017; accepted 21 October 2017

\author{
KEYWORDS \\ Clayey; \\ Sandy clay; \\ Gasoil; \\ Laboratory tests; \\ Mechanical properties; \\ Response Surface \\ Methodology (RSM)
}

\begin{abstract}
Oil and its derivatives such as gasoline, motor oil, and gasoil are being used in various industrial and non-industrial sectors as the main energy sources all over the world. Unfortunately, in the processes of exploration, transportation, and storage, they may spill or leak into the soil. Among them, gasoil, which is more widely used in different parts and machineries, has the largest contribution to contamination of the lands. Purgation of these areas is not always feasible or possible. Instead, they can be used in many engineering practices if the level of contamination is not high. In such cases, knowing the geotechnical properties of these areas is of great necessity and importance. In this study, extensive laboratory tests were performed on remolded clayey samples mixed with gasoil to evaluate their geotechnical properties. The Response Surface Methodology (RSM) was used to analyze the data and find behavioral equations. According to testing results and RSM outputs, decrease in Atterberg limits and increase in maximum dry density occur by increasing contamination. Also, both of the shear strength parameters (c and $f$ ) exhibit a turning point at $8 \%$ gasoil content, while their variation trends are quite in opposite directions.

(C) 2019 Sharif University of Technology. All rights reserved.
\end{abstract}

\section{Introduction}

Besides the air and water pollution, soil contamination has been studied due to its significant effects on the environment. Soil contamination can be studied from two points of view, one is the release rate of infection and its spread in the ground, and the other is its

*. Corresponding author. Tel.: 0098-21-64543031

E-mail addresses: fateme_mirh@yahoo.com (F. Mir

Mohammad Hosseini); drtebadi@gmail.com (T. Ebadi);

afeslami@aut.ac.ir (A. Eslami); mirh53@yahoo.com (S.M.

Mir Mohammad Hosseini); hamidrezajahan9069@gmail.com (H.R. Jahangard)

doi: $10.24200 /$ sci. 2017.4574 effects on soil properties. Different site pollutions with materials and petroleum products occur for various reasons. The leakage and spillage of gasoil from old and corroded storage tanks, pipelines, processing plants, and petroleum transportation facilities contaminate the surrounding soils. The extent of contamination depends on the filtration and retention properties of the soil [1-3].

Contamination due to chemicals and oil spills can influence the engineering behavior of soils. Severe environmental and ecological problems are caused by oil spills. They may also have adverse effect on engineering properties of soil such as shear strength, compressibility, and hydraulic conductivity. The effect of oil contamination on the engineering properties 
of soil has been increasingly focused on in recent years. Investigations have shown that the engineering properties and behavior of soil may be significantly influenced by chemical contamination [4-9].

It is recognized that remediation of soil is in practice costly and limited, especially in widely contaminated areas, due to the huge expenses demanded. An alternative solution could be the use of contaminated soil in engineering practices, such as embankments, road bases, backfills, etc. Thus, in addition to the environmental concerns about groundwater pollution and other possible effects, an investigation into the geotechnical characteristics of the contaminated soil is required. The investigation has also to be done to design a storage tank foundation on contaminated soils in a way to have satisfactory performance during the lifetime of the tank. The investigation also provides knowledge to revise the foundation design of the existing structures on contaminated sites.

A number of studies have already been carried out on the geotechnical properties of the soils contaminated by petroleum hydrocarbons [10-13]. Al-sanad et al. [14] and Al-sanad and Ismael [15] investigated the geotechnical properties of Kuwaiti oil contaminated sand. They carried out an extensive laboratory testing program to study the basic properties by doing compaction, permeability, triaxial, and consolidation tests. Contaminated specimens were prepared by mixing the sand with oil with the amount of $6 \%$ by weight. The results indicated a small reduction in strength and permeability and an increase in compressibility due to contamination.

Khamehchiyan et al. [16] performed a laboratory testing program to determine effects of crude oil contamination on geotechnical properties (including Atterberg limits, permeability, uniaxial compressive strength, direct shear tests, and compaction characteristics) on three soil types of CL, SP, and SM in the south of Iran. The results indicated decrease in strength, permeability, maximum dry density, optimum water content, and Atterberg limits.

Puri [4] studied the geotechnical aspects of contaminated sands and effects of oil contamination on compaction characteristics, shear strength, onedimensional compression, and hydraulic conductivity. Adverse effects of oil contamination on shear strength parameters and 20-25\% reduction in the friction angle of sand contaminated with oil were observed in the study.

Nazir [17] conducted a laboratory testing program to study the effect of motor oil contamination together with the effect of contamination duration on geotechnical properties of over-consolidated clay. Four parameters of Atterberg limits, unconfined compressive strength, coefficient of permeability, and compressibility characteristics were investigated. The studies revealed that the unconfined compressive strength was reduced by about $38 \%$ as compared to the reference value (uncontaminated).

A comprehensive set of laboratory tests were conducted on both uncontaminated and contaminated fine-grained soils containing different amounts of crude oil by Kermani and Ebadi [18]. The results indicated an increase in the angle of internal friction, maximum dry density, compression index, and Atterberg limits as well as a decrease in optimum water content and cohesion, as the oil content increased. Khosravi et al. [11] evaluated the geotechnical properties of gasoil-contaminated kaolinite. They carried out an extensive laboratory program that studied basic properties, namely Atterberg limits, consolidation, direct shear, and unconfined compression tests in clean and contaminated kaolinite specimens. Results indicated an increase in the cohesion and decrease in both the friction angle and compressibility of kaolinite soils with increasing the gasoil content.

More recently, Liu et al. [19] focused on engineering properties of kaolin clay contaminated by diesel oil. They carried out comprehensive tests on clay samples having oil contents of $4,8,12,16$, and $20 \%$ (by mass fraction). They found that as contamination degree of the kaolin clay increased, both the liquid and plastic limits decreased, but there was only a slight increase in plasticity index. They stated that the Unconfined Compressive Strength (UCS) of the oil contaminated kaolin clay was influenced by not only oil content but also curing period. They concluded that the oil content of $8 \%$ was the critical value for engineering property of the kaolin clay to transit from water-dominated towards oil-dominated characteristics.

In the early 2016, Nasehi et al. [20] studied the influence of gasoil contamination on geotechnical properties of only granular (fine and coarse) soils. They conducted some laboratory tests, such as plasticity, compaction, Unconfined Compressive Strength (UCS), and direct shear, on uncontaminated and artificially contaminated specimens with 3,6 , and $9 \%$ gasoil relative to dry weight of some SP and ML samples. The results indicated that a decrease in the friction angle and an increase in the cohesion of the soil with increase in gasoil content would occur. In addition, reduction in the maximum dry density and optimum moisture content was observed during the conduction of compaction tests. The increase in gasoil content also showed a direct effect on the increase in liquid and plastic limits of the silt samples.

Regarding the investigations performed so far, researchers have less considered the gasoil as contaminant among the petroleum products. However, gasoil as one of the most common oil derivatives in many engines and systems, such as transport, industry, agricultural machinery, and diesel engines, has an important con- 
Table 1. XRD analysis of the kaolinite.

\begin{tabular}{lccccccccc}
\hline Chemical components & L.O.I & $\mathrm{SiO}_{2}$ & $\mathrm{Al}_{2} \mathrm{O}_{3}$ & $\mathrm{Fe}_{2} \mathrm{O}_{3}$ & $\mathrm{TiO}_{2}$ & $\mathrm{Na}_{2} \mathrm{O}$ & $\mathrm{K}_{2} \mathrm{O}$ & $\mathrm{CaO}$ & $\mathrm{MgO}$ \\
Percentage (\%) & 8.9 & 64.4 & 21.2 & 0.26 & 0.05 & 1.11 & 1.15 & 2.2 & 0.73 \\
\hline
\end{tabular}

tribution to the pollution of the soils. Clayey soils, due to their fabrics and nature, may face more complicated and influential changes in their engineering properties compared with non-cohesive soils such as what was recently studied by Nasehi et al. [20]. However, in the past investigations, limited studies have been carried out even on granular and sandy soils.

In order to model the behavior of contaminated clayey soils, analyze the geotechnical data from laboratory tests, and find correlations of parameters, an appropriate method should be used. Factorial experimental design in combination with Response Surface Methodology (RSM), as a statistical analysis approach, is an efficient and widely used method to analyze, compare, and optimize the simultaneous application of different factors [21]. The Response Surface Methodology (RSM) is a combination of mathematical and statistical approaches used for modeling different phenomena and optimizing the experimental results as a function of various parameters [22]. The method, which has been used by many researchers, requires a limited number of experiments, being a simple and feasible optimization procedure.

In the current study, the effort has been attempted to investigate the geotechnical properties of fine soils contaminated by gasoil. A series of physical and mechanical tests were carried out on clayey soil samples mixed with different percentages of gasoil. To analyze the experimental data and extend the results for getting a general behavioral model indicating the engineering properties of fine soils contaminated by gasoil, the Response Surface Methodology (RSM) was used. The innovations of the current study can be classified as follows:

- Investigating the effect of gasoil contamination on the following geotechnical parameters of clayey soils:

- Atterberg limits (P.L., L.L., and P.I.),

- Compactability of the soil ( $w_{\text {opt. }}$ and $g_{d \max }$ ),

- Shear strength parameters $(C$ and $f)$,

- The role of non-cohesive fine contents.

- Developing experimental equations to predict changes of the above parameters using RSM.

The details of testing program, analyzing approach, and the main outcomes of this study are described in the following sections.

\section{Testing materials and methods}

\subsection{Materials}

Soil materials of this study included pure clay and sandy clays having different fine sand contents. The clay which was the main part of the studied soil was kaolinite and in the process of performing the study, some percentages of fine sand were added to it in order to determine and compare the effects of gasoil contamination on engineering properties of both pure and sandy clays. X-Ray Diffraction (XRD) was done to identify and analyze the composition of the clay. The results are shown in Table 1 . Table 2 summarizes the clay mineralogy. The grain size distribution of the clay, determined by a hydrometer (ASTM-D422), is shown in Figure 1. The sand is Firozkooh artificial fine sand (specified by grade No. F161). Tables 3 and 4 present the characteristics of the soils used in this research and Figure 2 shows the grain size distribution of the fine sand (ASTM-D422). The pure clay and fine sand used in this study are separately classified as low plastic clay (CL) and poorly graded sand (SP), respectively, based on the unified soil classification system (ASTMD2487). Table 5 shows the gas oil properties used in the current study.

\subsection{Response Surface Methodology (RSM)}

Factorial design and response surface methodology were used for experimental design. Based on the

Table 2. Clay mineralogy.

\begin{tabular}{ccc}
\hline Kaolinite & Feldespar & Silicon \\
\hline $51.57 \%$ & $16.22 \%$ & $32.21 \%$ \\
\hline
\end{tabular}

Table 3. The clay properties and indices.

\begin{tabular}{cccccc}
\hline PL & $\mathbf{L L}$ & $\mathbf{P I}$ & $\boldsymbol{G}_{\boldsymbol{s}}$ & $\begin{array}{c}\boldsymbol{g}_{\boldsymbol{d} \max } \\
\left(\mathrm{g} / \mathbf{c m}^{\mathbf{3}}\right)\end{array}$ & $\begin{array}{c}\boldsymbol{w}_{\text {opt }} \\
(\boldsymbol{\%})\end{array}$ \\
\hline 16 & 48 & 32 & 2.66 & 1.46 & 28.84 \\
\hline
\end{tabular}

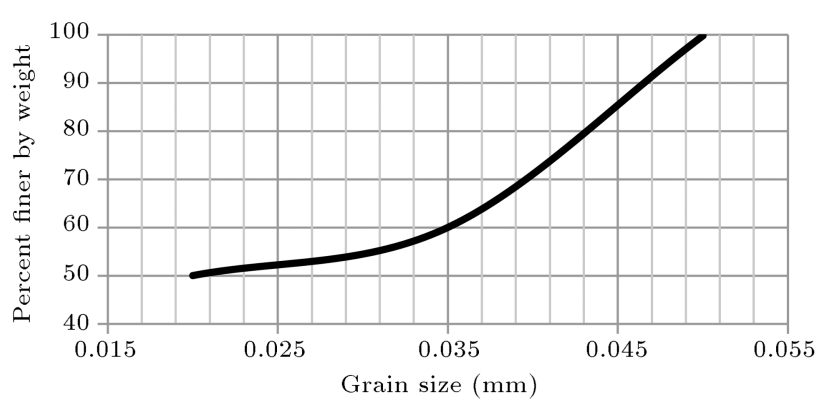

Figure 1. Grain size distribution curve of the kaolinite. 
Table 4. Firozkooh fine sand (F161) specifications.

\begin{tabular}{ccccccccc}
\hline $\boldsymbol{D}_{\mathbf{1 0}}(\mathbf{m m})$ & $\boldsymbol{D}_{\mathbf{3 0}}(\mathbf{m m})$ & $\boldsymbol{D}_{\mathbf{5 0}}(\mathbf{m m})$ & $\boldsymbol{D}_{\mathbf{6 0}}(\mathbf{m m})$ & $\boldsymbol{G}_{\boldsymbol{s}}$ & $\boldsymbol{e}_{\min }$ & $\boldsymbol{e}_{\max }$ & $\boldsymbol{C}_{\boldsymbol{u}}$ & $\boldsymbol{C}_{\boldsymbol{c}}$ \\
\hline 0.16 & 0.20 & 0.25 & 0.26 & 2.65 & 0.58 & 0.931 & 1.625 & 0.96 \\
\hline
\end{tabular}

Table 5. The gasoil properties (NIORDC, Iran).

\begin{tabular}{ccc}
\hline $\begin{array}{c}\text { Density in } 150^{\circ} \mathbf{C} \\
(\mathbf{k g} / \mathbf{L})\end{array}$ & $\begin{array}{c}\text { F.B.P (max) } \\
\left({ }^{\circ} \mathbf{C}\right)\end{array}$ & $\begin{array}{c}\text { Flash point (min) } \\
\left({ }^{\circ} \mathbf{C}\right)\end{array}$ \\
\hline $0.820-0.860$ & 385 & 54 \\
\hline
\end{tabular}



Figure 2. Grain size distribution curve of the fine sand.

information obtained from the pre-trial and studies for static tests, 2 parameters were examined as operating parameters and their boundaries determined. These two parameters were the sand ( $A$ or $x_{1}$ ) with the range of $(0-20 \%)$ and gasoil ( $B$ or $\left.x_{2}\right)$ with the range of $(0-$ $16 \%)$ as independent variables. They were coded at three levels between 1 and -1 . The ranges of the individual factors were chosen based on the preliminary studies and previous experience, and are presented in Table 6. The Design Expert 7 software was used for statistical analysis of experimental data by response surface methodology. Based on the number of the selected parameters, the software determined 13 runs for the tests consisting of 8 non-central points and 5 replicates at the center according to Central Composite Design (CCD). For the statistical calculations, the variables $X_{i}$ (the actual value of independent variable) were coded as $x_{i}$ (dimensionless value of the independent variable) according to the following equation $[22,23]$ :

$$
x_{i}=\left(X_{i}-X_{0}\right) / \delta X,
$$

where $X_{0}$ is the $X_{i}$ value in the central point and $\delta X$ represents the step change. The experimental data were fitted into the empirical second-order polynomial model. The second-order equation to predict the optimal condition is $[22,23]$ :

$$
Y=b_{0}+\sum_{i=1}^{n} b_{i} x_{i}+\sum_{i=1}^{n} b_{i i} x_{i}^{2}+\sum_{i=1}^{n-1} \sum_{j=i+1}^{n} b_{i j} x_{i} x_{j}
$$

where $Y$ is the predicted response by the model, $b_{0}$ is a constant, $b_{i}$ are linear coefficients, $b_{i i}$ are secondorder coefficients, $b_{i j}$ are interaction coefficients, and $x_{i}$
Table 6. Experimental design and the levels of

\begin{tabular}{|c|c|c|c|c|}
\hline \multirow{2}{*}{$\begin{array}{c}\text { Independent } \\
\text { variables }\end{array}$} & \multirow{2}{*}{ Symbol } & \multicolumn{3}{|c|}{ Coded levels } \\
\hline & & -1 & 0 & 1 \\
\hline Sand & $A$ & 0 & 10 & 20 \\
\hline Gasoil & $B$ & 0 & 8 & 16 \\
\hline
\end{tabular}
independent process variables.

Table 7. Composition of prepared and tested samples.

\begin{tabular}{cl}
\hline Number & \multicolumn{1}{c}{ Sample } \\
\hline 1 & Pure clay $+0 \%$ gasoil \\
2 & Pure clay $+4 \%$ gasoil \\
3 & Pure clay $+8 \%$ gasoil \\
4 & Pure clay $+12 \%$ gasoil \\
5 & Pure clay $+16 \%$ gasoil \\
6 & Clay $+10 \%$ sand $+0 \%$ gasoil \\
7 & Clay $+10 \%$ sand $+4 \%$ gasoil \\
8 & Clay $+10 \%$ sand $+8 \%$ gasoil \\
9 & Clay $+10 \%$ sand $+12 \%$ gasoil \\
10 & Clay $+10 \%$ sand $+16 \%$ gasoil \\
11 & Clay $+20 \%$ sand $+0 \%$ gasoil \\
12 & Clay $+20 \%$ sand $+4 \%$ gasoil \\
13 & Clay $+20 \%$ sand $+8 \%$ gasoil \\
14 & Clay $+20 \%$ sand $+12 \%$ gasoil \\
15 & Clay $+20 \%$ sand $+16 \%$ gasoil \\
\hline
\end{tabular}

and $x_{j}$ are the coded values corresponding to the tested variables $[23,24]$. The validity of the predicted model is verified by analysis of variance (ANOVA). The secondorder model quality is assessed by the correlation factor $\left(R^{2}\right)$ and analysis of the result is carried out using Fischer trial and probability value with $95 \%$ confidence level [22].

Predictive experiments for static tests, including the Atterberg limits (ASTM-D4318) and standard proctor tests (ASTM-D698), were performed to determine the physical indices and maximum dry density. Moreover, triaxial (ASTM-D4767) and direct shear (ASTM-D3080) tests were carried out to get the shear strength parameters. The details of samples prepared and tested are given in Table 7 . For the software input responses, 2 key responses from each test were chosen. Maximum dry density and optimum water content were the 2 responses of the compaction test. Atterberg limits have Plastic Limit (PL) and Liquid Limit (LL) as the responses. Direct shear and static triaxial tests 
also have 2 responses, which are cohesion and friction angle. The experimental tests, which were determined by the software, were done in soil mechanics laboratory of Amirkabir University of Technology. Then, the required responses for the tests were entered into the software in order to analyze and achieve an appropriate model.

\section{Sample preparation method}

As water content of the pure clay soil used in this study was zero percent, the soil did not require to be dried in the furnace and was only pulverized in order to pass through a size- 4 sieve. Then, the gasoil was added to the soil samples with the amounts of 0,8 , and $16 \%$ the weight of the dry soil (the combination and percentages of the materials were selected by the software). On the other hand, to make the sandy clay samples, the Firozkooh fine sand was mixed with pure clay in different percentages up to $20 \%$ the weight of the dry kaolinite. Accordingly, 15 samples were prepared for laboratory tests. For making samples contaminated with gasoil, the soil was mixed and stirred with gasoil until getting a homogenous soil-gasoil mixture. The same procedure was followed to prepare sandy clay samples (with or without gasoil). Then, all the specimens were housed in fully sealed plastic bags and kept in the temperature of $30^{\circ} \mathrm{C}$ for $7-10$ days for curing without any gasoil being evaporated. This period of time is consistent with the 3-7 days period proposed in the literature for soil-contaminant mixtures $[11,25]$. The temperature was chosen based on the average temperature within a reasonable depth in the oil facility and sites prone to similar contaminations [11]. All the specimens were prepared in their maximum dry densities and optimum water contents based on the results of compaction tests (as shown in Figure 3) were initially used.

\section{Testing results}

After 15 runs, based on a factorial design of two independent variables at three levels, the experimental results for the tests were obtained and the model analysis process began with analysis of variance. The ANOVA table and the resulting equation represent the prediction of the model by the software for geotechnical properties of soil parameters. One of the data of ANOVA by which the validity of the model is measured is the $p$ value. $P$ value is the probability of a given data with void hypothesis. The lower the amount of $p$ value $(<0.05)$, the more the validity and importance of the model will be. In this study, in order to validate the models predicted by the software, the coefficient $R^{2}$ s, analysis of variance, and normal probability plots for the remaining graphs will be investigated. The

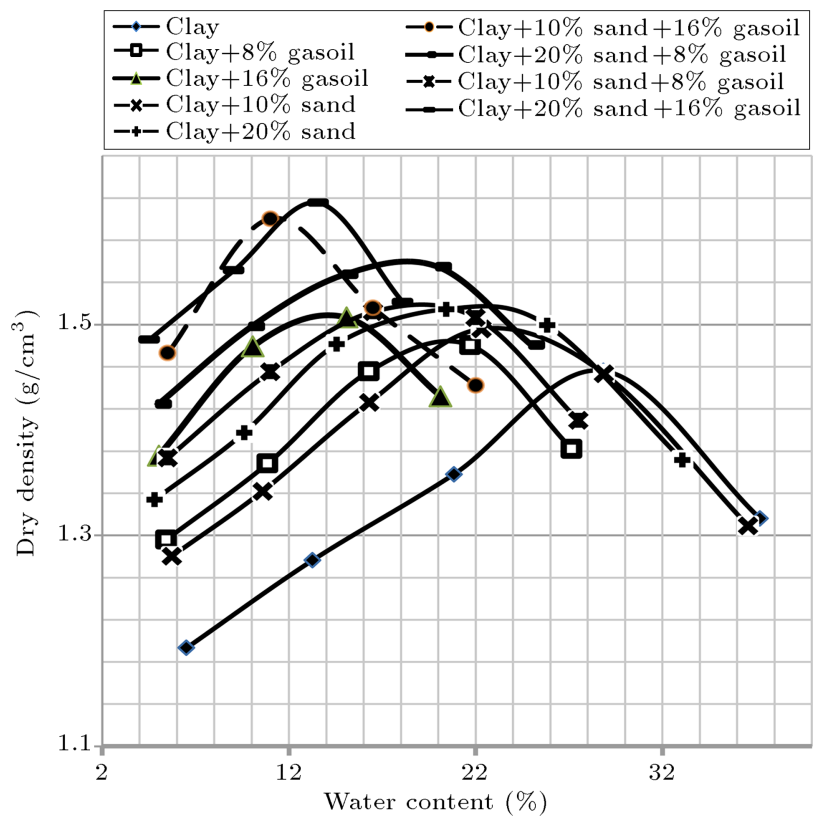

Figure 3. Results of compaction tests carried out on different contaminated samples.

values close to unity for coefficient of determination indicate the high validity of the model. In the normal plot of residuals, the closer the points to a straight line, the more normal the distribution will be. The results for these models as well as analyses of variances and equations are provided for the experiments in the following.

\subsection{Atterberg limits}

The LL (Liquid Limit), PL (Plastic Limit), and PI (Plastic Index) were measured and evaluated for 15 samples of clean and contaminated soils with 0,8 , and $16 \%$ gasoil by the weight of dry soil. In case of gasoil-contaminated soils, the regular equation of the water content in the soil, which is the ratio of weight of water to the weight of dry soil, due to the presence of gasoil and its effect on the fluid amount inside the voids, cannot be used. In order to investigate the effects of gasoil on the water content, an extensive laboratory study was done. Fifty specimens with different contents of soil, gasoil, and water were prepared. The specimens were classified in two groups. In both groups, the soil and water contents were both quite the same, changing in the ranges of 20-300 grams and 20\%-50\%, respectively. The only difference between these groups was that there was no gasoil content in the first one, while in the second one, the specimens were mixed with gasoil in the range of $4-20 \%$. Thus, after taking the samples out of the oven, each specimen from group 1 could be compared with its equivalent from group 2 for measuring the amount of gasoil loss in the oven for the known amounts of soil and initial water content. Since the F.B.P. (Fuel Boiling Point (see Table 3)) of the 
gasoil was considerably greater than that of the water, the amount of gasoil evaporation, after the period of complete evaporation of water in the samples in the oven, was not too great.

It was found that gasoil evaporation was a function of three factors, namely gasoil percentage, amount of soil, and water percentage, in the sample. The more the gasoil percentage, the higher its evaporation rate will be. The gasoil that does not evaporate will remain in the soil, unlike the water the whole amount of which will evaporate. It also follows that the higher the amount of soil, the lower the gasoil evaporation in the soil will be. In case of different water contents, no monotonous trend was achieved. Therefore, two correction factors of soil weight and water percentage were applied in calculation of gasoil evaporation. Then, the real water contents were calculated for the specimens by considering the gasoil evaporation effects (real water content $=$ moisture content of the specimen - gasoil evaporation content) by means of some graphs and equations. Figure 4 shows the correlation between sand and gasoil contents with gasoil evaporation. Increase in gasoil content leads to increase in gasoil evaporation.

Sand content reduction has almost the same effect on gasoil evaporation. Figure 5 indicates the relation of water contents in clay and gasoil contents with gasoil evaporation.

Based on the above corrections, the Atterberg

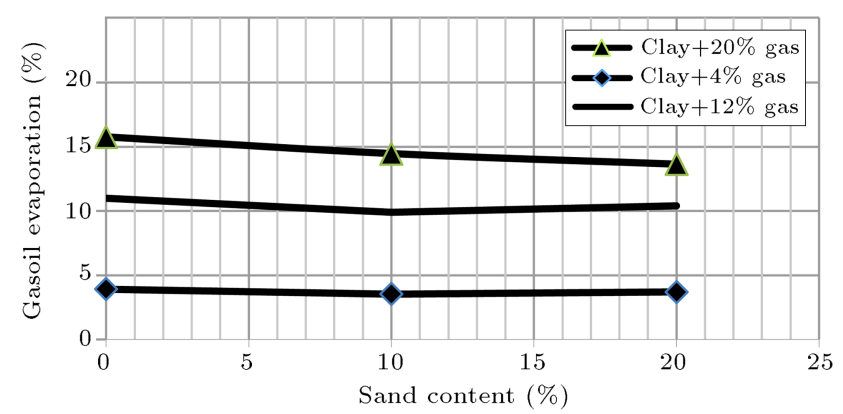

Figure 4. Relationship of gasoil evaporation with sand and gasoil contents.

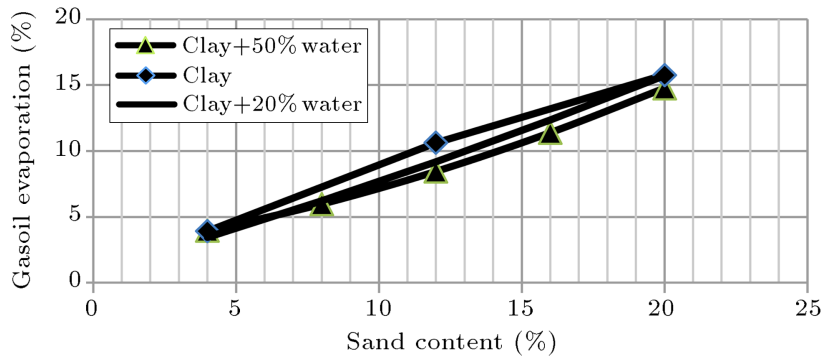

Figure 5. Relationship of gasoil evaporation with water and gasoil contents.

limits were calculated. As mentioned before, 2 responses (PL and LL) were chosen for Atterberg limits test. Tables 8 and 9 are ANOVA tables for the first and second responses of Atterberg limits. For variables, $p$ values lower than 0.05 indicate that the model terms are significant, while values greater than 0.1000 indicate that the model terms are not significant [26]. In addition, lack of fit $p$ value may possibly be due to a sentence in the model with void assumption, not the whole model. One of the most important factors that controls model verification is the amount of lack of fit $p$ value, which should be considered unimportant by the model. This means that the model has been validated and performs well. The PL and LL responses were fitted to the second order polynomial (Eqs. (3) and (4)) in terms of actual factors:

$$
\begin{aligned}
\mathrm{PL}= & +32.06-0.295 A-0.204 B+0.026 A . B \\
& -8.12 E-3^{*} A^{2}-0.19 B^{2} \\
\mathrm{LL}= & +47.88-0.474 A+0.052 B+0.036 A . B \\
& -0.010 A^{2}-0.049 B^{2}
\end{aligned}
$$

where PL is Plastic Limit (\%), LL Liquid Limit (\%), $A$ the fine sand content (\%), and $B$ the gasoil content $(\%)$.

In Tables 8 and 9 , the sentences $A$ and $B$ are very impressive in the model $(\ll 0.05)$. The lack of

Table 8. ANOVA for response surface quadratic model for plastic limit.

\begin{tabular}{lccccc}
\hline Source & Sum of squares & $\mathbf{d f}^{*}$ & Mean square & $\boldsymbol{F}$ value & $\begin{array}{c}\boldsymbol{p} \text { value } \\
\text { Prob }>\boldsymbol{F}\end{array}$ \\
\hline Model & 65.46 & 5 & 13.09 & 689.53 & $<0.0001$ \\
$A$ : sand (\%) & 18.63 & 1 & 18.63 & 981.03 & $<0.0001$ \\
$B$ : gasoil (\%) & 12.88 & 1 & 12.88 & 678.17 & $<0.0001$ \\
$A B$ & 2.49 & 1 & 2.49 & 131.16 & 0.0003 \\
$A^{2}$ & 0.88 & 1 & 0.88 & 46.36 & 0.0024 \\
$B^{2}$ & 2.13 & 1 & 2.13 & 111.94 & 0.0005 \\
Residual & 0.076 & 4 & 0.019 & & \\
Lack of fit & 0.024 & 1 & 0.024 & 1.39 & 0.3231 \\
$R^{2}=0.9988$, Adj $-R^{2}=0.9974$, Pred $-R^{2}=0.9854$. & \\
${ }^{*}$ df $=$ degrees of freedom (the number of model sentences minus one). &
\end{tabular}


Table 9. ANOVA for response surface quadratic model for liquid limit.

\begin{tabular}{lccccc}
\hline \multicolumn{1}{c}{ Source } & Sum of squares & $\mathbf{d f}^{*}$ & Mean square & $\boldsymbol{F}$ value & $\begin{array}{c}\boldsymbol{p} \text { value } \\
\text { Prob }>\boldsymbol{F}\end{array}$ \\
\hline Model & 157.73 & 5 & 31.55 & 457.11 & $<0.0001$ \\
$A$ : sand (\%) & 44.78 & 1 & 44.78 & 648.80 & $<0.0001$ \\
$B$ : gasoil (\%) & 27.42 & 1 & 27.42 & 397.34 & $<0.0001$ \\
$A B$ & 5.08 & 1 & 5.08 & 73.67 & 0.0004 \\
$A^{2}$ & 1.52 & 1 & 1.52 & 21.96 & 0.0054 \\
$B^{2}$ & 14.54 & 1 & 14.54 & 210.64 & $<0.0001$ \\
Residual & 0.35 & 5 & 0.069 & & \\
Lack of fit & 0.077 & 1 & 0.077 & 1.15 & 0.3439 \\
$R^{2}=0.9978$, Adj $-R^{2}=0.9956$, Pred $-R^{2}=0.9798$. &
\end{tabular}

Table 10. Full factorial CCD matrix for liquid limit.

\begin{tabular}{cccccc}
\hline \multirow{2}{*}{ Run order } & \multicolumn{2}{c}{ Factors } & \multirow{2}{*}{ Actual value } & Predicted value & Residual \\
\cline { 2 - 3 } & $\boldsymbol{A}:$ sand (\%) & $\boldsymbol{B}:$ gasoil (\%) & & 47.9 & 0.1 \\
\hline 5 & 0 & 8 & 48 & 38.2 & 0.3 \\
4 & 10 & 8 & 38.5 & 40.5 & 0.5 \\
7 & 10 & 8 & 41 & 34.1 & -0.1 \\
11 & 20 & 0 & 34 & 45.1 & -0.1 \\
1 & 0 & 8 & 45 & 37.4 & 0.1 \\
10 & 10 & 16 & 47.5 & 42.1 & -0.1 \\
12 & 0 & 8 & 36.18 & 36.1 & 0.1 \\
13 & 10 & 8 & 42.6 & 42.3 & 0.3 \\
8 & 10 & 8 & 42.5 & 42.3 & 0.2 \\
2 & 20 & 16 & 42.1 & 42.3 & -0.2 \\
9 & 20 & 0 & 42 & 42.3 & -0.3 \\
3 & 10 & 16 & 42.2 & 42.3 & -0.1 \\
6
\end{tabular}

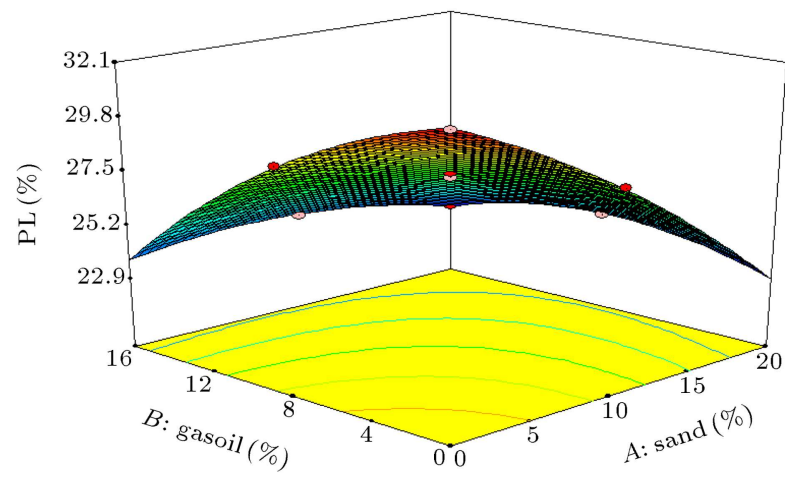

Figure 6. Response surface plot of the Plastic Limit $(\mathrm{PL})$.

fit $p$ values for the two models is insignificant from the viewpoint of the software. Table 10 shows an example of the predicted and actual values for the liquid limit. Response surface and contour plots of PL and LL are presented in Figures 6 and 7, respectively.

\subsection{Density and compaction characteristics}

To study the effects of gasoil on compaction behaviors of clay and sandy clay soils, standard proctor compaction tests were carried out on the selected samples.

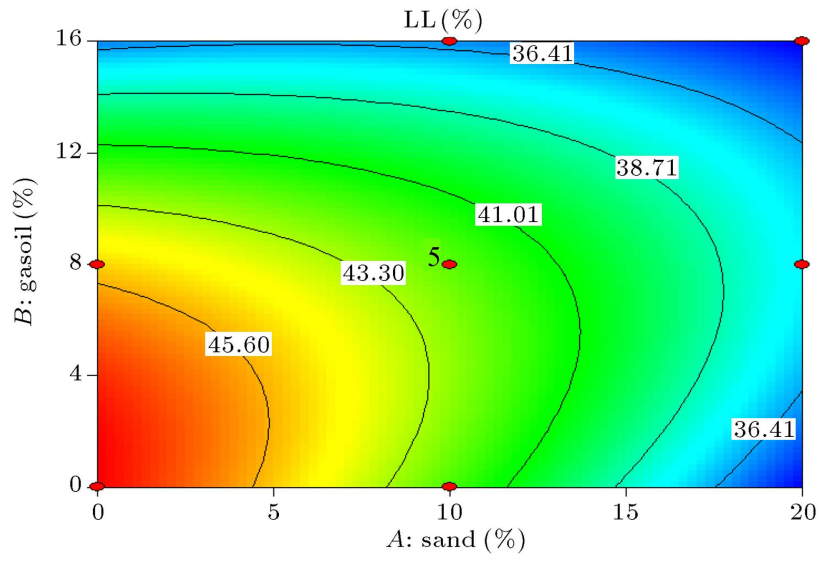

Figure 7. Contour plot of the Liquid Limit (LL).

For compaction test, 2 responses of maximum dry density and optimum water content were investigated. It is worth mentioning that to find the actual moisture content in the presence of gasoil, weight of evaporated gasoil was subtracted from moisture content of the whole specimen by knowing the weight of evaporated water. ANOVA tables for the first and second responses of compaction test were also prepared. The 
main factors $(A$ and $B)$ are very important and, based on the values obtained from the ANOVA tables, both show acceptable ranges $(\ll 0.05)$. Eqs. (5) and $(6)$ have been developed in terms of actual factors. These equations show the relationship between maximum dry density and optimum water content with sand and gasoil contents:

$$
\begin{aligned}
g_{d \max }= & +1.46+2.66 E-3 A+5.35 E-4 B \\
& +2.50 E-4 A B+1.48 E-4 B^{2}, \\
w_{\text {opt }}= & +24.91-0.247 A-0.435 B-2.06 E-3 A B \\
+ & 6.20 E-3 A^{2}-0.014 B^{2},
\end{aligned}
$$

where $g_{d \text { max }}$ is maximum dry density $\left(\mathrm{g} / \mathrm{cm}^{3}\right), w_{\text {opt }}$ optimum moisture content (\%), $A$ the fine sand content $(\%)$, and $B$ the gasoil content $(\%)$.

The lack of fit $p$ values for the two models is insignificant. Figure 8 also indicates the normal plot of residuals for maximum dry density. Response surface and contour plots of water content and maximum dry density are presented in Figures 9 and 10, respectively.

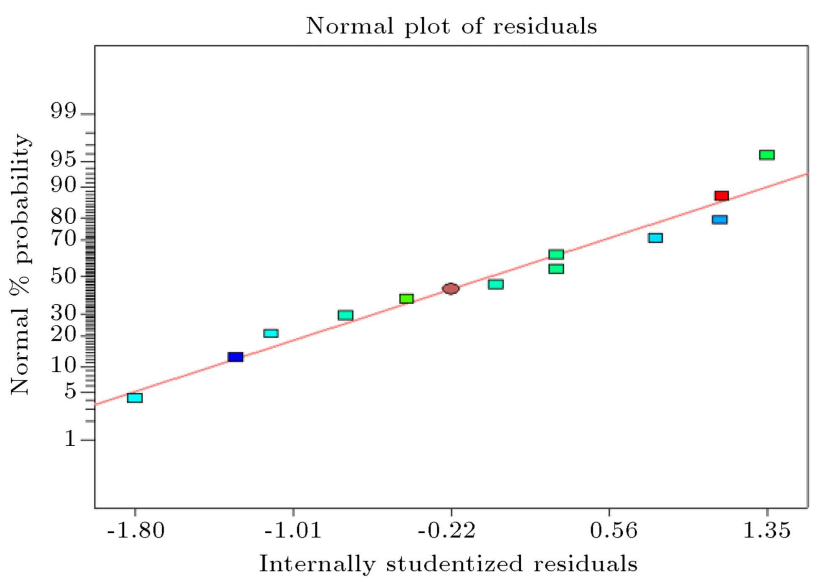

Figure 8. Normal plot of residuals for maximum dry density.

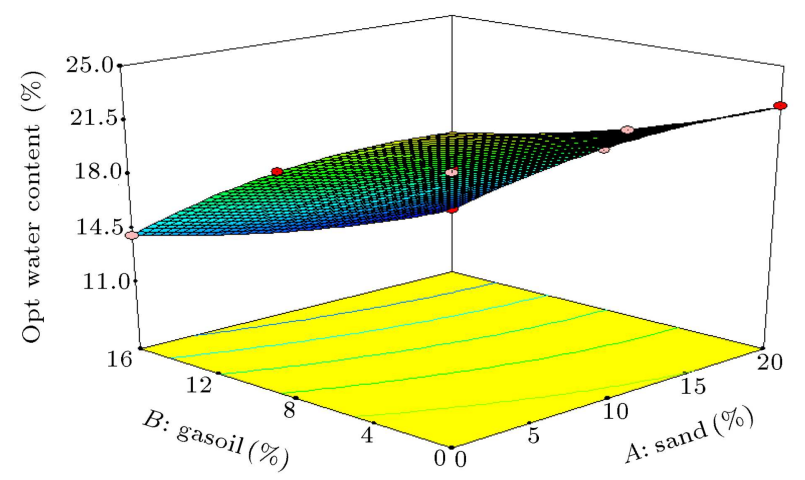

Figure 9. Response surface plot for the optimum water contents.

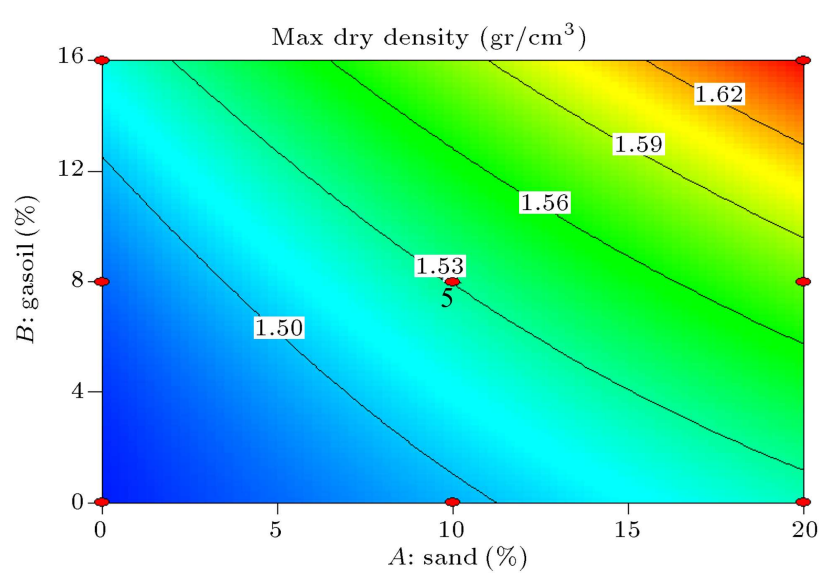

Figure 10. Contour plot of maximum dry density of the specimens.

\subsection{Shear strength parameters}

\subsubsection{Triaxial tests}

Isotropically consolidated undrained triaxial tests were performed on samples. All samples were $50 \mathrm{~mm}$ in diameter and $100 \mathrm{~mm}$ in height, and they were prepared at a relative density of $90 \%$ with the corresponding water content. The reason for this selection was that all samples showed dilative behavior and they were to be placed into the dry side of the compaction curve and far from saturated state. After mixing the soil with the desired contents of water and gasoil, the samples were kept in sealed plastic bags for 24 hours prior to the test. Then, for reaching the desirable compaction, wet tamping method was used. The tamping rod had the diameter of $2.5 \mathrm{~cm}$, which was one half the diameter of the specimen. In order to plot Mohre circles and obtain the shear strength parameters, each test was done for three confining stresses of 100,200 , and $300 \mathrm{KPa}$. The slope of failure envelop of the circles is internal friction angle and its intercept is cohesion. For the test data, ANOVA tables for the angle of internal friction and cohesion of the samples are also presented. Both of the main factors ( $A$ and $B$ ), based on the values obtained from the ANOVA tables, show acceptable ranges $(\ll 0.05)$. Eqs. $(7)$ and $(8)$ show the relation of internal friction angle and cohesion of the soil samples with fine sand and gasoil contents:

$$
\begin{aligned}
f= & +26.074+0.139 A-3.31 B-3.14 E-3 A B \\
& -2.34 E-3 A^{2}+0.190 B^{2}, \\
C= & +97.84-0.491 A+11.71 B+8.34 E-3 A B \\
& +0.014 A^{2}-0.904 B^{2},
\end{aligned}
$$

where $f$ is the angle of internal friction (degree), $C$ the cohesion $\left(\mathrm{g} / \mathrm{cm}^{2}\right), A$ the fine sand content $(\%)$, and $B$ the gasoil content $(\%)$. 
The lack of fit $p$ values for the two models is insignificant from the viewpoint of the model. Figure 11 also indicates the normal plot of residuals for internal friction angle. Response surface and contour plots of cohesion and internal friction angle are presented in Figures 12 and 13, respectively.

\subsubsection{Direct shear tests}

Direct shear tests were done on the selected samples. The tests were performed in a square shear box $(10 \mathrm{~cm} \times 10 \mathrm{~cm})$. Rate of shear was $1 \mathrm{~mm} / \mathrm{min}$ at

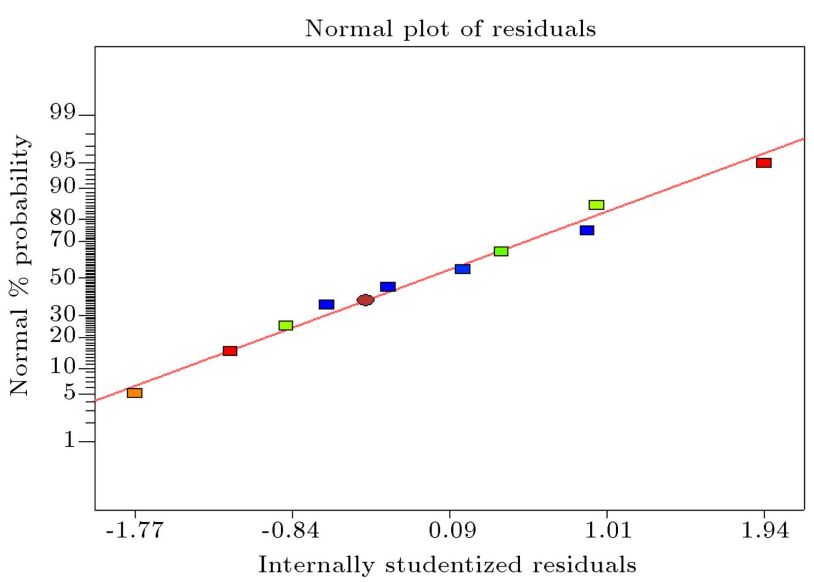

Figure 11. Normal plot of residuals for friction angles.

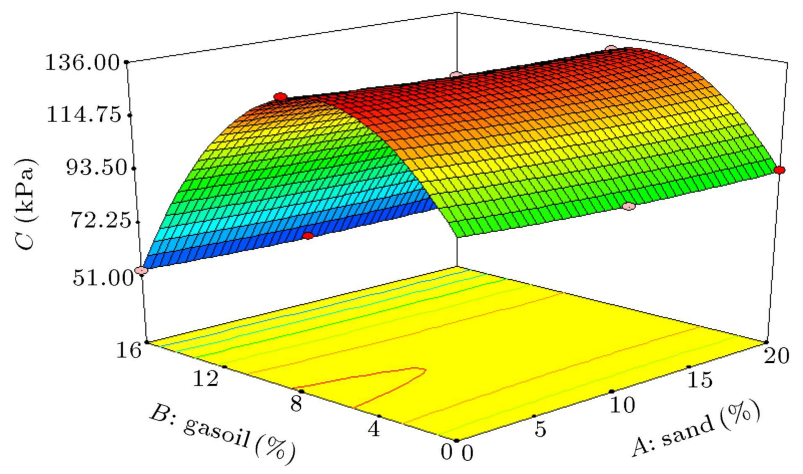

Figure 12. Response surface plot of the cohesion.

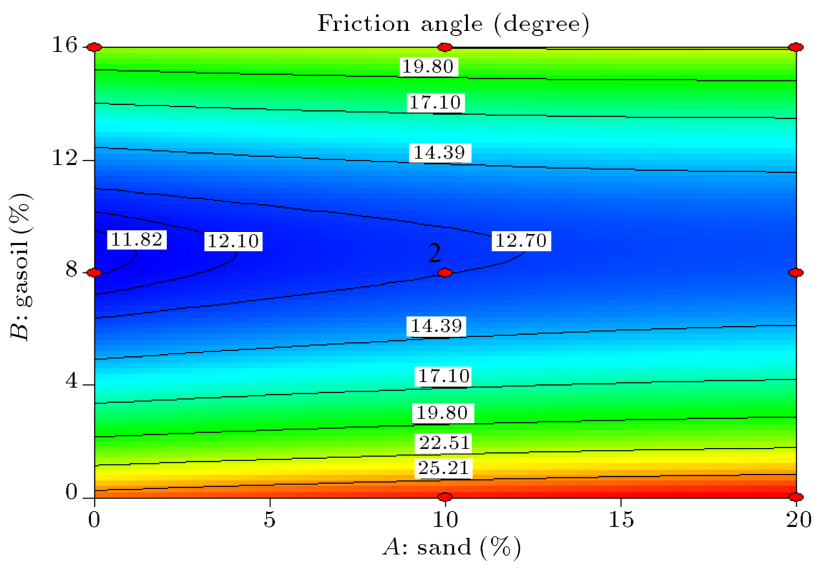

Figure 13. Contour plot of the friction angle. normal loads of 10, 20, and $30 \mathrm{~kg}$. Again, the ANOVA tables for the two main factors (cohesion and friction angle) based on the testing data are presented. The responses were fitted with the second order polynomial (Eqs. (9) and (10)) in terms of actual factors:

$$
\begin{aligned}
f= & +28.82+0.638 A-2.69 B-1.56 E-3 A B \\
& -0.018 A^{2}+0.159 B^{2}, \\
C= & +0.616-0.015 A+0.023 B+4.062 E-4 A B \\
& 2.94 E-4 A^{2}-2.22 E-3 B^{2},
\end{aligned}
$$

where $f$ is the angle of internal friction (degree), $C$ the cohesion $\left(\mathrm{g} / \mathrm{cm}^{2}\right), A$ the fine sand content (\%), and $B$ the gasoil content $(\%)$.

In the ANOVA table for the internal friction angle, $A, B$, and $B^{2}$ and in the ANOVA table for the cohesion, $A$ and $B^{2}$ are very important sentences in the models. Response surface and contour plots of internal friction angle and cohesion are presented in Figures 14 and 15 , respectively.

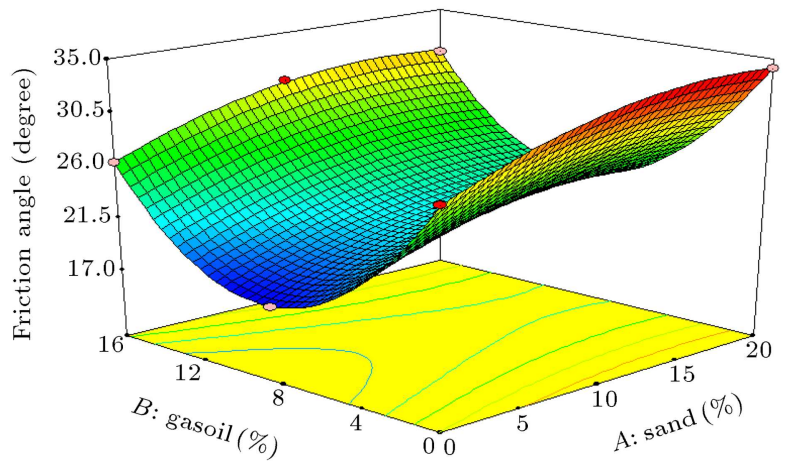

Figure 14. Response surface plot of the friction angle.

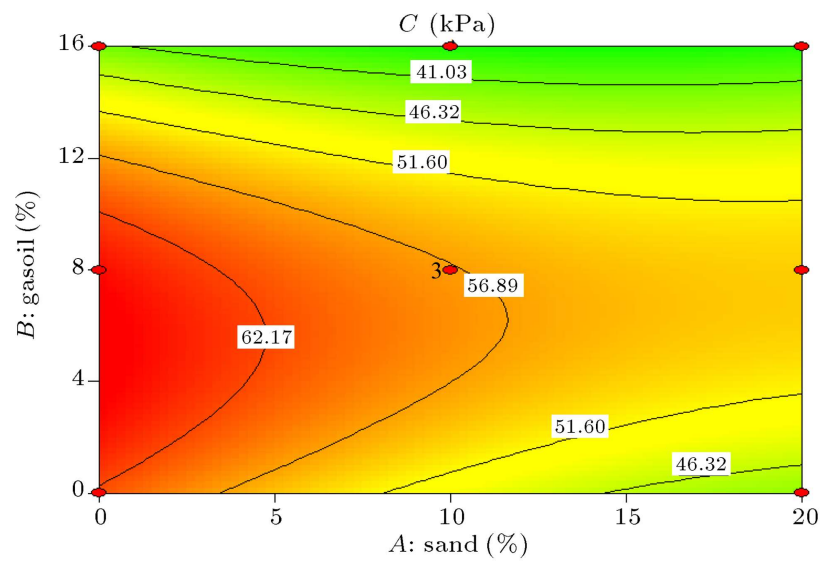

Figure 15. Contour plot of the cohesion. 


\section{Discussion}

\subsection{Atterberg limits}

As it can be seen in the response surface plot of PL and contour plot of LL (Figures 6 and 7 ), the results show a decrease in limits with increasing gasoil and sand contents in specimens. This reduction in Atterberg limits can be explained by double-layer theory of clays. The interaction of the short-range repulsion force with the long-range attraction between clay particles may have a profound influence on the engineering properties of the soil [27]. The compressibility of kaolinite with non-polar fluids like gasoil is highly sensitive to the value of the dielectric constant; double layers cannot develop in non-polar fluids [28]. The liquid limit values decrease consistently with decrease in the dielectric constant of the pore fluid $[29,30]$. The two forces that act between the clay particles are the diffuse double layer repulsion and the van der Waals attraction [30]. Decreasing dielectric constant of the pore fluid compresses the diffuse double layer thickness around the clay particles and in turn, the electrostatic repulsion, which can cause coagulation [30,31]. Thus, when the gasoil is mixed with soil, it surrounds the soil particles and then, the water reaction with soil particles is reduced. As a result, the thickness of double-layer water decreases [16]. A decrease in Atterberg limits occurs in the gasoil contaminated soil. It can also be seen that the liquid limit depends on physicochemical factors and, to a lesser degree, on mechanical factors other than the pore fluid density. Meegoda and Ratnaweera [32] studied the mechanical and physicochemical factors that controlled liquid limit of soil. They stated that if water was used as pore fluid, the influence of mechanical factors would remain the same. However, if an organic fluid was used instead of water, then the physical properties of the fluid such as viscosity would influence the liquid limit. The physicochemical factors due to low dielectric constant values would cause the clay to behave more like a granular material, in the presence of oil contamination, thus lowering the liquid limit [16]. These results are consistent with the studies of Khamehchiyan et al. [16] and Olgun and Yildız [30]. As it can be seen, the more the sand content, the less will be the Atterberg limits. It is because sand makes the texture of the samples more granular.

\subsection{Density and compaction characteristics}

In Figures 9 and 10, as the gasoil content increases, the maximum dry density increases and the response surface gradually decreases with optimum water content. In sandy clay specimens, increasing the percentage of sand to pure clay also increases the maximum dry density and decreases the optimum water content. This improvement in compaction characteristics can be attributed to the lubricating effect of the gasoil, which is due to the oil films coating on the individual clay particles and the clay groups $[18,33]$. In addition, as the results of Atterberg limits tests represent, the soil plasticity decreases due to gasoil contamination. A reduction in soil plasticity may lead to better compaction. Compactability is an important parameter for soils that are used as paving materials. This change in properties enhances the use of soil in embankments for road or other geotechnical structures [18]. The gasoil has lubricating effect and decreases the friction between soil particles. Thus, gasoil content increment increases the compaction efficiency because of the higher lubrication. It means that with a certain amount of energy consumption, higher maximum dry density will be obtained with lower optimum water content, because a small amount of gasoil has more influential role than water in friction reducing process. Fine sand increase has the same effect as the gasoil increase on the maximum dry density and optimum water content on pure clay samples; however, when the two friction reducing factors (sand particles and gasoil) are added to the clayey soils, the increase in the maximum dry density and decrease in the optimum moisture content will be doubled. As a result, increase in the intensity of the compression efficiency is achieved. It seems that in case of adding sand to the pure clay, the efficiency is more than that for the pure clay. However, this is not the optimal condition yet. In gasoil contents less than $8 \%$, the effects cannot be amplified; but in gasoil contents more than $8 \%$, sand particles can be more inoculated with gasoline. Thus, the effects can be intensified and the efficiency of the compaction effort would be the most.

\subsection{Triaxial tests}

Typical results for variations of shear strength parameters versus gasoil contamination obtained from triaxial tests are given in Figures 16 and 17. It can be seen that cohesion increases before $8 \%$ gasoil and then, decreases;

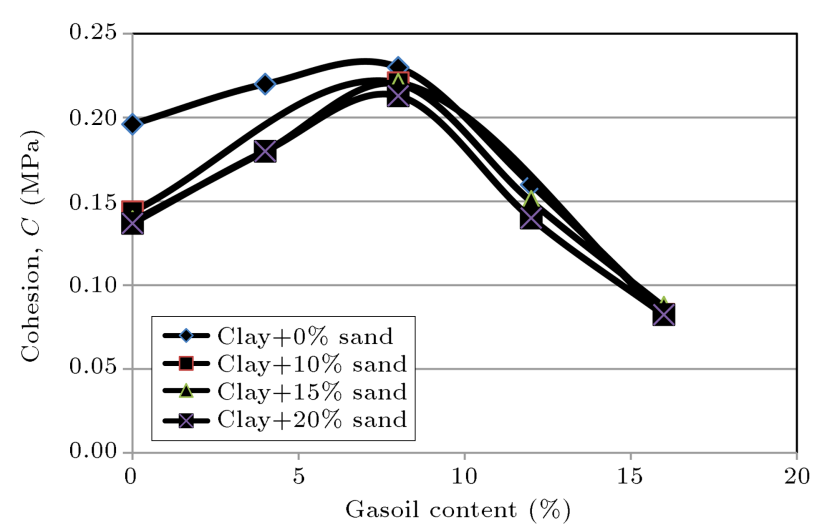

Figure 16. Variations of cohesion versus gasoil content in triaxial tests. 


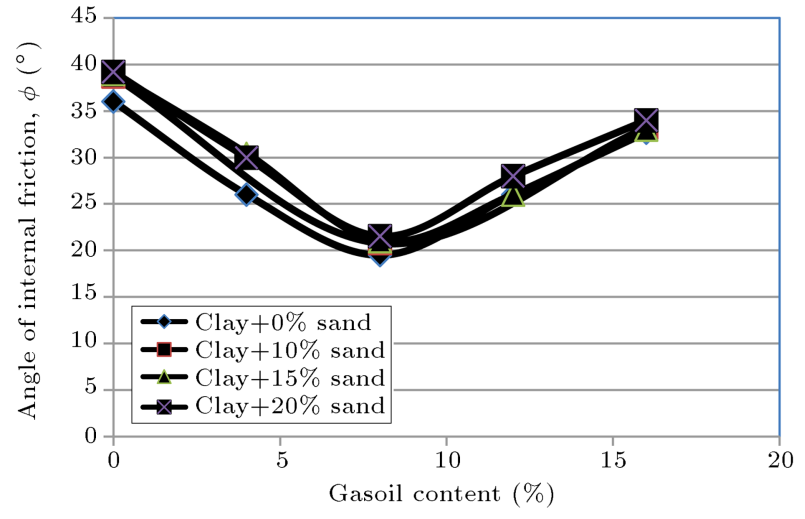

Figure 17. Variations of friction angle versus gasoil content in triaxial tests.

but, friction angle has an inverse trend. Therefore, increase in gasoil up to $8 \%$ leads to increase in cohesion; but, when gasoil increases to $16 \%$, cohesion decreases. This effect of gasoil on cohesion may relate to charged structure of clay plates with gasoil. Adding fine sand to pure clay increases the friction angle, because the sample texture changes from quite plastic mode to a mixture with grained materials. In Figure 13 contour plot of friction angle indicates that the friction angle of pure clay in the condition of optimal compaction is 25.4 degrees. Adding 10\% and 20\% fine sand changes this angle to 27.3 and 27.85 degrees, respectively. Gasoil in general has decreasing role in friction angle. This role is because of the lubricating effect of gasoil that covers the external surfaces of the particles like a thin oil film and reduces the friction and conflict between the particles. Increasing gasoil content up to $8 \%$ decreases the friction angle to 11.72 degrees, while increasing gasoil content up to $16 \%$ raises the friction angle to 21.93 degrees. Based on Figures 16 and 17, the important occurrence is that the point of change in trend of variations of friction angle is exactly the same as that for cohesion variations. The interpretation of this needs more detailed studies on interaction between clay, sand, water, and gasoil particles as well as the physicochemical behaviors of microstructures in tested specimens.

\subsection{Direct shear tests}

Changing trends of friction angle and cohesion as well as impact mechanisms of gasoil on cohesion and friction angle have compatibility and strong resemblance with the results of triaxial tests, but the amounts and quantities of the parameters are different. This fact relates to the mechanism and structure of the shear box that impose a certain failure surface and rigid boundary conditions on samples in comparison with the triaxial apparatus.

\section{Summary and conclusions}

To investigate the engineering properties of fine soils contaminated by gasoil, a laboratory testing program based on the RSM was carried out. A type of pure clay (kaolinite), namely CL, in the unified soil classification system and clay mixed with different amounts of fine sand (SP in USCS) were used as the fine materials in this study. The gasoil was added to specimens with different weight percentages up to $16 \%$ according to software selection. The samples were entirely mixed with gasoil and cured for 7-10 days in room temperature inside sealed plastic bags.

Plasticity indices as well as the density and compaction characteristics of the specimens were measured and shear strength parameters of the samples prepared at $90 \%$ relative density were evaluated and investigated. Four models were developed for the tests. Based on the results, different conclusions were driven, the most important of which are as follows:

- Both the Plastic Limit (PL) and Liquid Limit (LL) of fine soils are reduced as the gasoil content increases up to $16 \%$. The rate of decreasing for pure clay soils is slightly higher than that for sandy clay soils;

- In constant compaction effort, as the amount of the gasoil contamination increases (up to $16 \%$ ), the maximum dry density increases and the optimum moisture content decreases. These variations for pure clay soils are more considerable than those for sandy clay soils;

- The shear strength parameters of fine soils exhibit opposite variations with increase in the gasoil contamination. While cohesion of the samples increases up to $8 \%$ gasoil content, after which it starts decreasing, internal friction angle decreases up to $8 \%$ gasoil content, after which it start increasing. These adverse effects of gasoil content may be attributed to the difference of shear parameters in nature; in one parameter, chemical reactions play the decisive role while in the other, the mechanical behavior of the particles is determinative;

- In this study, by using RSM and designing some geotechnical tests, the engineering characteristics of contaminated fine soils were obtained with a fewer number of tests. Also, different equations were developed for predicting the main geotechnical parameters of clayey soils contaminated with gasoil in terms of fine sand and gasoil contents of the layers.

\section{References}

1. Fine, P., Graber, E.R., and Yaron, B. "Soil interactions with petroleum hydrocarbons abiotic processes", Soil Technology, 10(1), pp. 133-153 (1997).

2. Pathak, P., Singh, D.N., Asce, F., Pandit, G.G., and Apte, P.R. "Establishing sensitivity of distribution 
coefficient on various attributes of a soil contaminated system", Journal of Hazardous Toxic and Radioactive Waste, ASCE, 18, pp. 64-75 (2014).

3. Hong, S., Zhengtao, H., Xingang, L., and Guozhong, W. "Influence of soil and hydrocarbon properties on the solvent extraction of high-concentration weathered petroleum from contaminated soils", Environmental Science and Pollution Research, 21(9), pp. 74-84 (2014).

4. Puri, V.K. "Geotechnical aspects of oil-contaminated sands", Soil and Sediment Contamination, Taylor $\&$ Francis, 9(4), pp. 359-374 (2000).

5. Rahman, Z.A., Hamzah, U., Taha, M.R., Ithnain, N.S., and Ahmad, N. "Influence of oil contamination on geotechnical properties of basaltic residual soil", American Journal of Applied Sciences, 7, pp. 954-961 (2010).

6. Gupta, M.K. and Srivastava, R.K. "Evaluation of engineering properties of oil- contaminated soils", Journal of the Institution of Engineers (India), 90, pp. 37-42 (2010).

7. Jia, Y.G., Wu, Q., Shang, H., Yang, Z.N., and Shan, H.X. "The influence of oil contamination on the geotechnical properties of coastal sediments in the Yellow River delta", Bulletin of Engineering Geology and the Environment, 70(3), pp. 517-525 (2011).

8. Abousnina, R.M., Manalo, A., Shiau, J., and Lokuge, W. "Effect of light crude oil contamination on the physical and mechanical properties of fine sand", Soil \& Sediment Contamination: An International Journal, 8(24), pp. 833-845 (2015).

9. Ojuri, O. and Epe, G. "Strength and leaching characteristics of crude oil contaminated sandy soils stabilized with sawdust ash-cement", Geo-Chicago 2016: Sustainable Waste Management and Remediation, Chicago-Illinoise, pp. 582-590 (2016).

10. Cook, E.E., Puri, V.K., and Shin, E.C. "Geotechnical characteristics of crude oil-contaminated sands", Proc. of the 2nd Int. Offshore Polar Eng. Conf., San Francisco, USA, pp. 384-387 (1992).

11. Khosravi, E., Ghasemzadeh, H., Sabour, M.R., and Yazdani, H. "Geotechnical properties of gas oilcontaminated kaolinite", Engineering Geology, Elsevier, 166, pp. 11-16 (2013).

12. Pinedo, J., Ibanez, R., Lijzen, J.P.A., and Irabien, A. "Assessment of soil pollution based on total petroleum hydrocarbons and individual oil substances", Journal of Environmental Management, 130, pp. 72-79 (2013).

13. Khan, S.A., Tan, S.J., Abdul Rahman, E.K., and Muneerah, Dk.N. "Effect of hydrocarbon contamination and subsequent remedial treatment on the engineering properties of soil", Proceeding of the 5th Brunei International Conference on Engineering and Technology (BICET 2014), Brunei (2015).
14. Al-Sanad, H.A., Eid, W.K., and Ismael, N.F. "Geotechnical properties of oil contaminated Kuwaiti sand", Journal of Geotechnical Engineering, ASCE, 121, pp. 407-412 (1995).

15. Al-Sanad, H.A. and Ismael, N.F. "Aging effect on oil contaminated Kuwaiti sand", Journal of Geotechnical \& Geoenvironmental Engineering, ASCE, 123, pp. 290-293 (1997).

16. Khamehchiyan, M., Charkhabi, A.H., and Tajik, M. "Effects of crude oil contamination on geotechnical properties of clayey and sandy soils", Engineering Geology, Elsevier, 89, pp. 220-229 (2007).

17. Nazir, A.K. "Effect of motor oil contamination on geotechnical properties of over consolidated clay", Alexandria Engineering Journal, 50, pp. 331-335 (2011).

18. Kermani, M. and Ebadi, T. "The effect of oil contamination on the Geotechnical properties of finegrained soils", Soil and Sediment Contamination: An International Journal, Taylor \& Francis Group, 21, pp. 655-671 (2012).

19. Liu, Z.B., Liu, S.Y., and Cai, Y. "Engineering property test of kaolin clay contaminated by diesel oil", Journal of Central South University China, 22(12), pp. 48374843 (2015).

20. Nasehi, S.A., Uromeihy, A., Nikudel, M.R., and Morsali, A. "Influence of gasoil contamination on geotechnical properties of fine and coarse-grained soils", Journal of Geotechnical and Geological Engineering, 34(1), pp. 333-345 (2016).

21. Gomez, F. and Sartaj, M. "Optimization of field scale bio-piles for bioremediation of petroleum hydrocarbon contaminated soil at low temperature conditions by response surface methodology (RSM)", Int. Biodeterior. Biodegrad, 89, pp. 103-109 (2014).

22. Kalali, A., Ebadi, T., Rabbani, A., and Sadri Moghaddam, S. "Response surface methodology approach to the optimization of oil hydrocarbon polluted soil remediation using enhanced soil washing", Int. J. Environ. Sci. Tech., Springer, 8(2), pp. 389-400 (2011).

23. Montgomery, D.C., Design and Analysis of Experiments, 4th. Ed., John Wiley and Sons, USA (1996).

24. Myers, R.H. and Montgomery, D.C., Response Surface Methodology: Process and Product Optimization Using Designed Experiments, 2nd. Ed., John Wiley and Sons, USA (2002).

25. Singh, S.K., Srivastava, R.K., and John, S. "Settlement characteristics of clayey soils contaminated with petroleum hydrocarbons", Soil Sediment Contamination, 17, pp. 290-300 (2008).

26. Mehrabi, N., Soleimani, M., Sharififard, H., and Madadi Yeganeh, M. "Optimization of phosphate removal from drinking water with activated carbon using response surface methodology (RSM)", Desalination and Water Treatment, Taylor \& Francis, 57(33), pp. 15613-15618 (2015). 
27. Albert, T.Y. "Diffuze double-layer equations in SI units", J. of Geotech. Eng., ASCE., 118(12), pp. 20002005 (1992).

28. Di Matteo, L., Bigotti, F., and Ricco, R. "Compressibility of kaolinitie clay contaminated by ethanolgasoline blends", J. of Geotech. \& Geoenvr. Eng., $A S C E$, 137, pp. 846-849 (2011).

29. Sridharan, A., El-Shafei, A., and Miura, N. "A study on the dominating mechanisms and parameters influencing the physical properties of Ariake clay", International Association of Lowland Technology Journal, 2, pp. 55-70 (2000).

30. Olgun, M. and Yıldız, M. "Effect of organic fluids on the geotechnical behavior of a highly plastic clayey soil", Applied Clay Science, Elsevier, 48, pp. 615-621 (2010).

31. Kaya, A. and Fang, H.Y. "Experimental evidence of reduction in attractive and repulsive forces between clay particles permeated with organic fluids", Canadian Geotechnical Journal, Technical Note, 42, pp. 632-640 (2005).

32. Meegoda, N.J. and Ratnaweera, P. "Compressibility of contaminated fine grained soils", Geotechnical Testing Journal, 17(1), pp. 101-112 (1994).

33. Ur-Rehman, H., Abduljauwad, S.N., and Akram, T. "Geotechnical behavior of oil-contaminated finegrained soils", Electronic. J. of Geotech. Eng., 12A, pp. 15-23 (2007).

\section{Biographies}

Fatemeh Mir Mohammad Hosseini Completed her BSc in Civil Engineering Faculty of Amirkabir University of Technology, and her MSc in Environmental Faculty of Tehran University. At present, she is the PhD student of Environmental Group in Civil \& Environmental faculty of Amirkabir University. Her research topic in $\mathrm{PhD}$ studies is investigating the static and dynamic properties of fine cohesive soils contaminated by gasoil by means of extensive monotonic and cyclic testings.

Taghi Ebadi is an Assistant Professor in Environmental Group of Civil and Environmental faculty of Amirkabir University of Technology. He received his $\mathrm{PhD}$ (1376) from Concordia University in Canada and his MSc (1370) from Amirkabir University of Technology. His main research interests are geo-environmental studies by emphasizes on the laboratory and field investigations of contaminants on soils.

Abolfazl Eslami is a Professor in Geotechnical group of Civil and Environmental Faculty of Amirkabir University of Technology. He received his $\mathrm{PhD}$ (1375) from Ottawa University in Canada and his MSc (1367) from Amirkabir University of Technology. His main research interests are soil bearing capacity studies by emphasizes on the soil improvements methods and techniques.

Seyed Majdeddin Mir Mohammad Hosseini is a Professor of Geotechnical Group of Civil and Environmental Faculty of Amirkabir University of Technology. He received his $\mathrm{PhD}$ (1366) from Leeds University in UK and his MSc (1355) from Tehran University. His main research interests are soil dynamics and geotechnical earthquake engineering with focusing on laboratory works.

Hamid Reza Jahangard Completed his BSc in Civil Engineering Faculty of Tehran University. He did his MSc studies in Civil and Environmental Faculty of Amirkabir University of Technology and carried out his $\mathrm{MSc}$ research project on investigation of cyclic strength of fine soils contaminated by gasoil. 